\title{
Recent advances in understanding the phenotypes of
}

\section{osteoarthritis [version 1; peer review: 2 approved]}

\author{
Ali Mobasheri (iD1-4, Simo Saarakkala², Mikko Finnilä2, Morten A. Karsdal4, \\ Anne-Christine Bay-Jensen (1D4, Willem Evert van Spil 5,6
}

\footnotetext{
${ }^{1}$ Department of Regenerative Medicine, State Research Institute Centre for Innovative Medicine, Vilnius, 08661, Lithuania

${ }^{2}$ Research Unit of Medical Imaging, Physics and Technology, University of Oulu, Oulu, FI-90014, Finland

${ }^{3}$ Centre for Sport, Exercise and Osteoarthritis Research Versus Arthritis, Queen's Medical Centre, Nottingham, UK

${ }^{4}$ ImmunoScience, Nordic Bioscience Biomarkers and Research, Herlev, DK-2730, Denmark

${ }^{5}$ Division of Internal Medicine \& Dermatology, Department of Rheumatology \& Clinical Immunology, University Medical Center Utrecht, Utrecht, The Netherlands

${ }^{6}$ Rheumatology, Dijklander Hospital, 1620 AR Hoorn, The Netherlands
}

V1 First published: 12 Dec 2019, 8(F1000 Faculty Rev):2091

https://doi.org/10.12688/f1000research.20575.1

Latest published: 12 Dec 2019, 8(F1000 Faculty Rev):2091

https://doi.org/10.12688/f1000research.20575.1

\section{Abstract}

Recent research in the field of osteoarthritis (OA) has focused on understanding the underlying molecular and clinical phenotypes of the disease. This narrative review article focuses on recent advances in our understanding of the phenotypes of OA and proposes that the disease represents a diversity of clinical phenotypes that are underpinned by a number of molecular mechanisms, which may be shared by several phenotypes and targeted more specifically for therapeutic purposes. The clinical phenotypes of OA supposedly have different underlying etiologies and pathogenic pathways and they progress at different rates. Large OA population cohorts consist of a majority of patients whose disease progresses slowly and a minority of individuals whose disease may progress faster. The ability to identify the people with relatively rapidly progressing OA can transform clinical trials and enhance their efficiency. The identification, characterization, and classification of molecular phenotypes of rapidly progressing $\mathrm{OA}$, which represent patients who may benefit most from intervention, could potentially serve as the basis for precision medicine for this disabling condition. Imaging and biochemical markers (biomarkers) are important diagnostic and research tools that can assist with this challenge.

\section{Keywords}

osteoarthritis, molecular endotype, clinical phenotype, imaging, biomarker, patient stratification, clinical trials, drug development

\section{Open Peer Review \\ Approval Status \\ 1 2 \\ version 1 \\ 12 Dec 2019 \\ Faculty Reviews are review articles written by the prestigious Members of Faculty Opinions. The articles are commissioned and peer reviewed before publication to ensure that the final, published version is comprehensive and accessible. The reviewers who approved the final version are listed with their names and affiliations. \\ 1. Rik J U Lories, University Hospitals Leuven, KU Leuven, 3000 Leuven, Belgium \\ 2. Charles J. Malemud, Case Western Reserve University School of Medicine, University Hospitals Cleveland Medical Center, Cleveland, USA}

Any comments on the article can be found at the end of the article. 
Corresponding author: Ali Mobasheri (ali.mobasheri.1968@gmail.com)

Author roles: Mobasheri A: Conceptualization, Writing - Original Draft Preparation, Writing - Review \& Editing; Saarakkala S: Writing Original Draft Preparation, Writing - Review \& Editing; Finnilä M: Writing - Original Draft Preparation, Writing - Review \& Editing; Karsdal MA: Conceptualization, Writing - Original Draft Preparation, Writing - Review \& Editing; Bay-Jensen AC: Writing - Original Draft Preparation, Writing - Review \& Editing; van Spil WE: Conceptualization, Writing - Original Draft Preparation, Writing - Review \& Editing

Competing interests: Anne-Christine Bay-Jensen and Morten A. Karsdal are full-time employees and shareholders of Nordic Bioscience, a small-medium enterprise involved in biomarker identification, validation, and development. Ali Mobasheri has consulted for the following companies in the last three years: Abbvie, Aché Laboratórios Farmacêuticos S.A., AlphaSights, Galapagos, Guidepoint Global, Kolon TissueGene, Pfizer Consumer Health (PCH), Servier, Bioiberica S.A. and Science Branding Communications.

Grant information: Ali Mobasheri has received funding from The European Commission Framework 7 programme (EU FP7; HEALTH.2012.2.4.5-2, project number 305815; Novel Diagnostics and Biomarkers for Early Identification of Chronic Inflammatory Joint Diseases). The author also wishes to acknowledge funding from the European Commission through a Marie Curie Intra-European Fellowship for Career Development grant (project number 625746; acronym: CHONDRION; FP7-PEOPLE-2013-IEF). He also wishes to acknowledge financial support from the European Structural and Social Funds through the Research Council of Lithuania (Lietuvos Mokslo Taryba) according to the activity 'Improvement of researchers' qualification by implementing world-class R\&D projects' of Measure No. 09.3.3-LMT-K-712 (grant application code: 09.3.3-LMT-K-712-01-0157, agreement No. DOTSUT-215) and further support from the European Structural and Social Funds through Lietuvos Mokslo Taryba according to the Programme "Attracting Foreign Researchers for Research Implementation", Grant No 0.2.2-LMTK-718-02-0022. Ali Mobasheri, Willem Evert Van Spil, and Anne BayJensen have received funding from The Innovative Medicines Initiative Joint Undertaking under grant agreement No. 115770, resources of which are composed of financial contribution from the European Union's Seventh Framework programme (FP7/2007-2013) and EFPIA companies' in-kind contribution.

The funders had no role in study design, data collection and analysis, decision to publish, or preparation of the manuscript.

Copyright: (c) 2019 Mobasheri A et al. This is an open access article distributed under the terms of the Creative Commons Attribution License, which permits unrestricted use, distribution, and reproduction in any medium, provided the original work is properly cited.

How to cite this article: Mobasheri A, Saarakkala S, Finnilä M et al. Recent advances in understanding the phenotypes of osteoarthritis [version 1; peer review: 2 approved] F1000Research 2019, 8(F1000 Faculty Rev):2091

https://doi.org/10.12688/f1000research.20575.1

First published: 12 Dec 2019, 8(F1000 Faculty Rev):2091 https://doi.org/10.12688/f1000research.20575.1 


\section{Introduction}

Osteoarthritis (OA) is the most common disorder of synovial joints, such as the knees, hips, and hands, and the most significant source of societal cost in older adults ${ }^{1}$. Conservative estimates from the Global Burden of Disease 2010 study suggest that of all the chronic health conditions, hip and knee OA was ranked as the 11th highest contributor to global disability and 38th highest contributor to disability-adjusted life years (DALYs) ${ }^{2}$. It is estimated by the World Health Organization that by the year 2050, 130 million people will suffer from OA worldwide and 40 million will be severely disabled, highlighting the significant societal burden that this serious disease will present ${ }^{3}$.

Joint damage in OA may occur through repeated and excessive mechanical loading on the joint and the cumulative impact of low-grade inflammation over time, or through injury, sustained during the life course $\mathrm{e}^{4}$. Loss of articular cartilage structure and function is one of the major hallmarks of $\mathrm{OA}^{5-7}$. The gradual articular cartilage degradation, bone changes, low-grade inflammation and synovitis cause: joint pain, anatomical changes, and swelling; impairing mobility and reducing quality of life ${ }^{8}$. OA symptoms are debilitating and, as well as causing physical impairment, can affect the psychosocial wellbeing of patients, paving the way for novel psychological interventions?. In the absence of disease-modifying treatments, the management of OA must be tailored to the individual and focus on core treatments, including self-management and education, exercise, and weight loss as relevant ${ }^{1}$.

Recent evidence suggests that $\mathrm{OA}$ is a heterogeneous and multifaceted disease with multiple molecular and clinical phenotypes ${ }^{10}$. The ability to classify patients into different groups and identify patients with relatively rapid OA progression can significantly transform OA clinical trials and enhance their efficiency. This approach has been applied to rheumatoid arthritis $(\mathrm{RA})^{11}$ and is a well-established segmentation and stratification strategy for identifying "clinicopathobiologic clusters" (another term that may be used to describe molecular endotypes) $)^{12}$ and developing targeted therapeutics for asthma ${ }^{13}$. Here we provide a narrative review of advances in understanding the molecular and clinical phenotypes of OA over the last 3 years. We also discuss biomarkers that have potential to be useful for molecular phenotyping of OA patients ${ }^{14}$. We can learn a great deal from the molecular phenotyping approaches that are currently used in other disease areas and apply them in basic research and clinical development for OA.

\section{Clinical and molecular endotypes of osteoarthritis}

Emerging evidence over the last few years suggests that OA is a heterogeneous and multifaceted disease with multiple molecular and clinical phenotypes ${ }^{10,14}$. Identifying phenotypes of OA is an important research priority because it allows us to gain a better understanding of the pathways and mechanisms that may be involved in each distinct phenotype and target them more effectively using a variety of preventive and treatment strategies $^{15}$.
In the field of asthma research, the concept of phenotypes has already paved the way for a comprehensive molecular and cellular classification of different forms of asthma ${ }^{16}$. However, in this field, the clinical phenotype was defined as the presentation of the disease in an individual and focuses on the presentation of the disease rather than the molecular mechanisms underlying it. Whereas, the molecular endotype, alludes to the pathogenesis at the molecular and/or cellular level, ignoring its presentation. See Box 1 and Box 2 for further details. Insights from the asthma field may be deployed in the future, to benefit the OA research community, as efforts to create and disseminate similar, consensus-based definitions in the OA field are currently ongoing.

\section{Box 1. Definition of endotype}

In biology, endotype may be defined as a specific molecular pathway that explains the observable properties of a phenotype. In medicine, an endotype is a subtype of a disease or condition, which is defined by a distinct functional or pathobiological mechanism. Endotype implies the presence of a well-defined molecular mechanism and is distinct from a phenotype (see Box 2). Molecular endotypes may be defined by specific cells or biomarker molecules in blood or other body fluids.

\section{Box 2. Definition of phenotype}

In biology, phenotype can also be defined as "observable properties of a living organism that are produced by the interactions of the genotype and the environment". In medicine, a phenotype may be any observable characteristic or trait of a disease, such as morphology, development, biochemical or physiological properties, or behavior, without any implication of a molecular mechanism or pathway. In clinical medicine, patients with common characteristics are often grouped together to guide therapy and improve management. Phenotyping is very useful for studying, diagnosing, and treating any disease, particularly those that are inflammatory and degenerative. However, at the present time, clinical phenotypes are the most common method of subgrouping. There are several problems with clinical phenotyping. First, there may be no specific tests or biomarkers that identify a particular phenotype compared to another phenotype. Therefore, diagnosis is usually left to the judgment of the clinician or researcher and may not be definitive. Second, there are not consensus definitions for specific subgroups. For this reason, poorly understood subgroups may go undiagnosed and untreated and lumped together with others.

\section{Clinical phenotypes of osteoarthritis}

A systematic review of the literature conducted by Dell'Isola and colleagues in 2016 examined the current evidence for the existence of groups of variables which may point towards the existence of distinct clinical phenotypes in the knee OA population ${ }^{17}$. They reviewed a total of 24 studies and, through qualitative synthesis of the available evidence, they found evidence for six distinct knee OA phenotypes (see Figure 1). They found that $84 \%$ of the subjects examined could be classified into six major phenotypes and that $12 \%$ of the total could be classified into an "inflammatory" category according to 


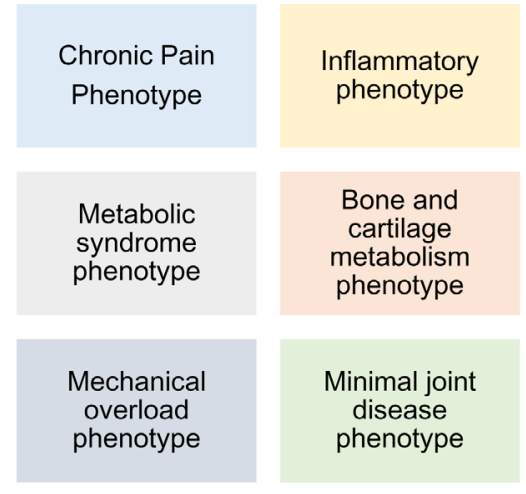

Figure 1. Clinical phenotypes of knee osteoarthritis. Clinical phenotypes of knee osteoarthritis, as originally identified by Dell'Isola et al. ${ }^{17}$.

synovitis/effusion scores from the MOAKS (Magnetic Resonance Imaging [MRI] Osteoarthritis Knee Score).

A number of trials of anti-IL-1 agents did specifically focus on OA patients with associated synovitis. A recent phase II clinical trial of the anti-IL- $1 \alpha / \beta$ dual variable domain immunoglobulin lutikizumab (ABT-981) in patients with knee OA and synovitis showed limited improvement in the WOMAC pain score and no improvement in synovitis. Trials of other IL-1 inhibitors in knee OA showed similar results ${ }^{18}$. ABT-981 was also tested in erosive hand $\mathrm{OA}$ in a phase IIa, placebocontrolled, randomized trial. Again, neither pain nor imaging outcomes improved compared with placebo ${ }^{19}$. These outcomes are in clear contrast with ample data showing that IL-1 $\beta$ is a critical pro-inflammatory cytokine mainly activating the MAPK (mitogen-activated protein kinase) pathway, eventually resulting in elevated levels of matrix metalloproteinases that can cause cartilage matrix protein degradation ${ }^{20}$. This might indicate that IL-1 $\beta$ alone may be less pivotal in driving OA pathobiology than initially hypothesized. Yet other factors might also be relevant, such as the disease stage of the study subjects and suboptimal outcome measures. Moreover, selecting particular molecular endotypes rather than clinical phenotypes may still help identify patient subgroups that could benefit from targeted anti-inflammatory strategies such as IL-1 $\beta$ blockade.

In a subsequent paper published two years later, Dell'Isola et al. used data from the Osteoarthritis Initiative (OAI) to classify a sample of individuals with knee OA into pre-defined groups characterized by specific variables that may be linked to different disease mechanisms and compare these phenotypes for demographic and health outcomes ${ }^{21}$. They selected 599 patients from the OAI database to conduct the study. Findings from existing studies and open source data were used to identify cut offs of key variables for each phenotype. After each of the three steps of the selection, classified patients were discounted from subsequent stages. Those who fell into more than one phenotype were assigned a separate 'complex knee OA' group. Using the OAI dataset, the authors were able to allocate phenotypes for $84 \%$ of cases with an overlap of $20 \%$. Disease duration was shorter in the minimum joint disease while they found that the chronic pain phenotype included more women (81\%). This subsequent study demonstrated the feasibility of using a classification system for knee OA subjects and placing them in distinct phenotypes based on subgroup-specific characteristics ${ }^{21}$.

An expert working group assembled by the European Society for Clinical and Economic Aspects of Osteoporosis, Osteoarthritis, and Musculoskeletal Diseases (ESCEO) and the European Union Geriatric Medicine Society (EUGMS) suggested possible patient profiles in OA. Herreo-Beaumont et al. discussed the existence of four distinct phenotypes, including biomechanical, osteoporotic, metabolic, and inflammatory, and proposed that further characterization of these phenotypes would help to properly stratify patients with OA in clinical trials ${ }^{22}$.

A review article published in 2014 by Karsdal et al. proposed five potential phenotypes, including mechanotransduction, hormonal, metabolic, auto-inflammation, and genetic subtypes. Their motivation for reviewing the literature was to propose the idea of finding the "right patients" for the "right drug" in OA. They suggested key drivers of the disease and their speculated impact on the rate of disease progression, which influences the duration of clinical trials. They also proposed that the drivers of OA progression may be divided into at least three different categories: bone, cartilage, and inflamed synovium, the key tissues that make up the synovial joint. These tissues may represent different disease subgroups; alternatively, they may represent the predominant and tissue-specific pathologies during a particular stage of disease. Optimal therapy may be considered the ability to detect and target each of these stages or subgroups of disease. Although the review by Karsdal et al. did not take a systematic approach, it did highlight methods for possible segregation of OA patients that would allow the identification of patient subtypes, particularly the small population of OA patients whose disease is driven by inflammation, proposing that this group offers pharmaceutical companies the "low hanging fruit" and may be ideally suited for personalized healthcare and for the development of smarter and more targeted therapies ${ }^{23}$.

\section{Molecular endotypes of osteoarthritis}

As explained above, molecular OA endotypes are disease subtypes that are defined by distinct molecular mechanisms and signaling pathways. When investigating mechanisms of disease development and progression, we should recognize that different clinical OA phenotypes may consist of overlapping molecular endotypes that may be identified by the presence of specific cells or biomarker molecules in blood or synovial fluid, which is the most suitable proximal tissue fluid for assessing the molecular and cellular taxonomy of OA subtypes. We already know a great deal about the structural and molecular alterations that occur in the cartilage ECM and within chondrocytes in OA cartilage (Figure 2).

The structural alterations that are seen in the articular cartilage, synovium, subchondral bone, and other peri-articular tissues using imaging techniques such as radiography, $\mathrm{MRI}^{24}$, 


\section{Structural Alterations}

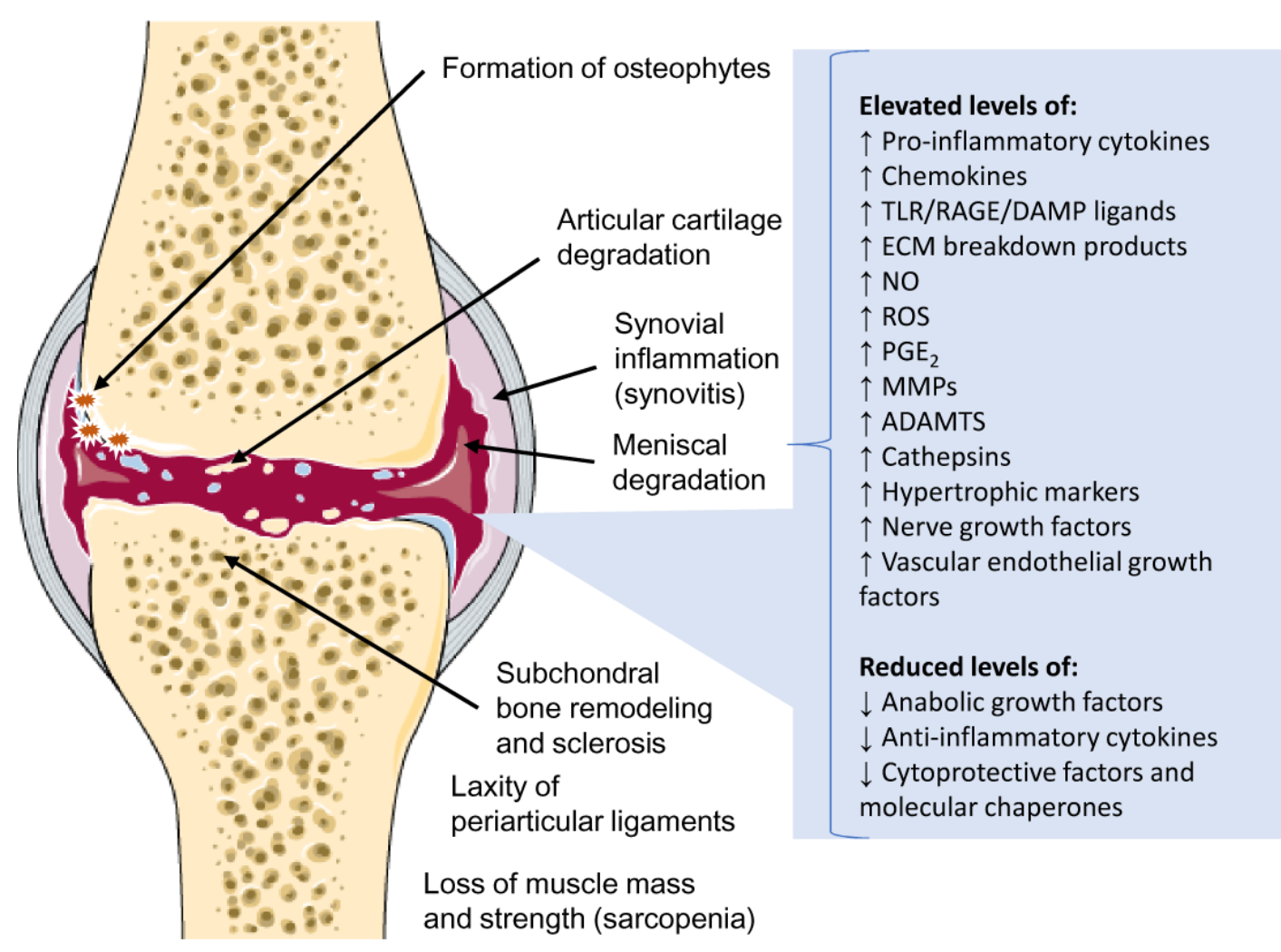

Figure 2. Summary of the major structural and molecular alterations in osteoarthritis. Molecular alterations in the micro-environment of chondrocytes and changes in the structure of the extracellular matrix (ECM) alter the behavior and physiology of chondrocytes. ADAMTS, a disintegrin and metalloproteinase with thrombospondin motifs; MMPs, matrix metalloproteinases; NO, nitric oxide; PGE, prostaglandin E2; RAGE, receptor for advanced glycation end-product; ROS, reactive oxygen species; TLR, Toll-like receptor.

ultrasonography ${ }^{25}$, and computed tomography (CT) are preceded by molecular and cellular changes that occur many years before structural changes come to light ${ }^{26}$. Indeed, the "molecular phase" of the disease can remain latent for decades ${ }^{27}$. The most recent definition of OA published by the Osteoarthritis Research Society International (OARSI) states "the disease manifests first as a molecular derangement (abnormal joint tissue metabolism) followed by anatomic, and/or physiologic derangements (characterized by cartilage degradation, bone remodeling, osteophyte formation, joint inflammation and loss of normal joint function)" ${ }^{28}$. The updated definition also mentions the role of pro-inflammatory pathways of innate immunity which implicate the innate immune system in OA pathogenesis ${ }^{29}$. The molecular alterations in early OA can be studied using epigenomics, transcriptomics, proteomics, and metabolomic and lipidomic platforms $^{30}$ and by monitoring changes in the chondrocyte secretome $^{31}$. More extensive alterations in the cartilage ECM occur in the intermediate and later stages of the disease, and these can be monitored using assays of biochemical markers derived from ECM breakdown ${ }^{32-34}$.

There are a number of early molecular alterations that occur within chondrocytes and in their surrounding micro-environment.
These are important changes and can provide clues about molecular endotypes. Recent research on the senescence-associated secretory phenotype (SASP) in chondrocytes from OA cartilage has revealed phenotypic alterations at the cellular level, including chondrosenescence ${ }^{35,36}$, metabolic alterations at the mitochondrial and glycolytic levels, and extensive molecular changes in the secretome and the micro-environment of OA cartilage (detailed discussion of these changes is beyond the scope of this review, but they are worth mentioning and summarizing in Figure 3).

\section{The inflammatory osteoarthritis phenotype}

Discussion of all the putative endotypes of $\mathrm{OA}$ is beyond the scope of this review. However, the inflammatory phenotype is worth discussing in more detail, as it has implications for the development of therapeutic strategies that have failed and future therapies that may be more targeted. We have known about the existence of an inflammatory phenotype of OA for more than 40 years (since 1975) but have not paid careful attention to the historic literature. In a paper published over 40 years ago, George E. Ehrlich described a cohort of predominantly menopausal females who presented with a deforming and inflammatory OA, some of whom went on to develop inflammatory changes characteristic of RA but clearly did not have $\mathrm{RA}^{37,38}$. 


\section{Senescence associated secretory phenotype (SASP) in chondrocytes from osteoarthritic cartilage}

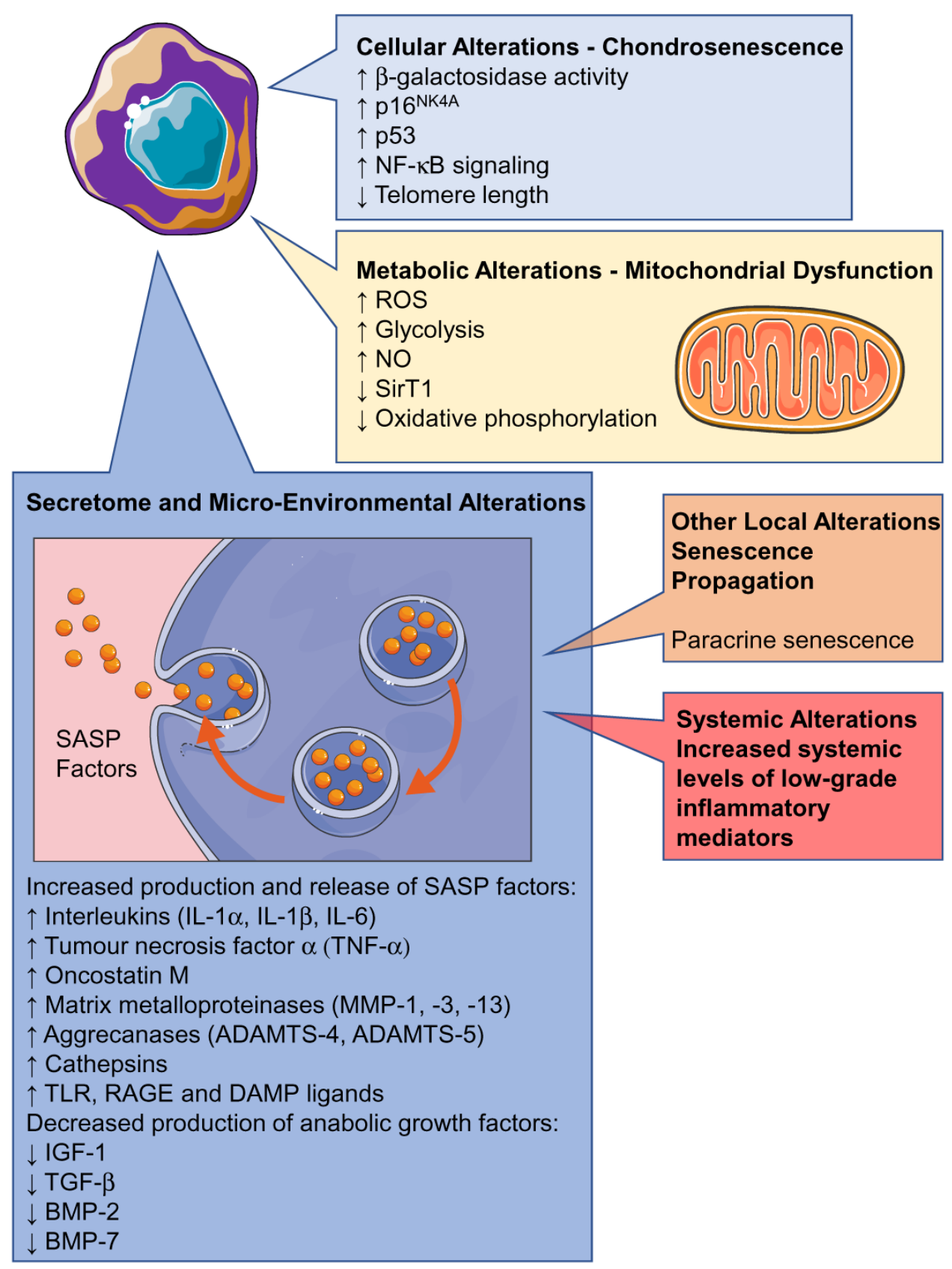

Figure 3. Senescence-associated secretory phenotype (SASP) in chondrocytes from osteoarthritis cartilage, highlighting phenotypic alterations at the cellular level in cells ${ }^{35,36}$. BMP, bone morphogenetic protein; DAMP, damage-associated molecular pattern; IGF-1, insulinlike growth factor-1; NF- $\mathrm{kB}$, nuclear factor $\mathrm{\kappa B}$; NO, nitric oxide; RAGE, receptor for advanced glycation end-product; ROS, reactive oxygen species; TGF- $\beta$, transforming growth factor- $\beta$; TLR, Toll-like receptor.

This classic study is as relevant now as it was when it was originally published. Inflammation is important, but it is not always present at all OA stages. If we take a cross-section of a large population of OA patients at all stages of disease progression, we will find only a small proportion that will display inflammatory features. This does not mean that inflammation is not important in OA; it simply highlights the temporal aspects of its manifestation. Clearly, inflammation is an important molecular endotype in OA. Synovial inflammation (synovitis) is believed to contribute to the pathophysiology and symptoms of OA through 
increased local production of pro-inflammatory cytokines, chemokines, and mediators of joint tissue damage ${ }^{39}$. Therefore, treating the most aggressive forms of synovial inflammation holds great promise for symptom and structure modification in $\mathrm{OA}^{40}$. However, in order to do this, we must possess sensitive tools to detect aggressive synovitis. Inflammation of the synovial membrane may occur in both the early and the late phases of OA and is associated with mononuclear cell infiltration of the synovial membrane and alterations in the adjacent cartilage that are similar to those seen in $\mathrm{RA}^{41,42}$. From a clinical perspective, Hoffa's synovitis in the knee and the formation of osteophytes are relatively strongly associated with the presence of knee pain. We know that the presence of Hoffa's synovitis and osteophytes in any region of the knee joint is significantly associated with the presence and severity of pain in $\mathrm{OA}^{43}$. MRI and Doppler ultrasonography can be used to diagnose synovitis and identify the most aggressive forms in the knee ${ }^{44}$. The sensitivities for detecting effusion and synovitis using ultrasonography are excellent ${ }^{44}$. Correlating ultrasound imaging with histopathological findings and MRI findings gives us the ability to identify those patients with aggressive synovitis. Ultrasound also allows us to assess the late-stage OA changes in the knee ${ }^{45}$. Therefore, we might already have the tools; we simply need to use them for patient stratification. We also have the opportunity to combine imaging biomarkers with biochemical markers to develop combination biomarkers that can define each molecular endotype, allowing us to start defining the underlying endotypes.

\section{Discussion}

It is very likely that multiple molecular and clinical phenotypes of OA exist and that they are important to take into account in OA research and clinics. The first goal is to identify the clinical phenotypes and clearly define their constituent molecular endotypes. This is a challenging task, as clearly many of these are interconnected and mechanistically linked (Figure 4 and Figure 5). For example, a low-repair phenotype may be an overarching age-related phenotype that may overlap with multiple different phenotypes, resulting in a set of people with more rapidly progressing $\mathrm{OA}$ and/or in need of more aggressive treatment targeting multiple mechanisms. Likewise, a mechanical phenotype may provoke several molecular mechanisms, such as a cartilage phenotype, that later becomes inflammatory, which may be particularly important within an obese phenotype (a high-fat or high-adiposity phenotype). Clearer definition of the molecular endotypes is needed, and much more research is needed to achieve this. A better understanding of the underlying molecular endotypes will allow us to define the clinical phenotypes more clearly and develop biomarker panels that can predict disease progression and determine which patients may have a better capacity for joint repair. We may even be able to distinguish between patients who will benefit from earlier total joint replacement surgery and those who can keep their joint for a longer time. This can lead to significant savings in healthcare management, enhanced clinical trials, and more effective OA drug development pipelines.

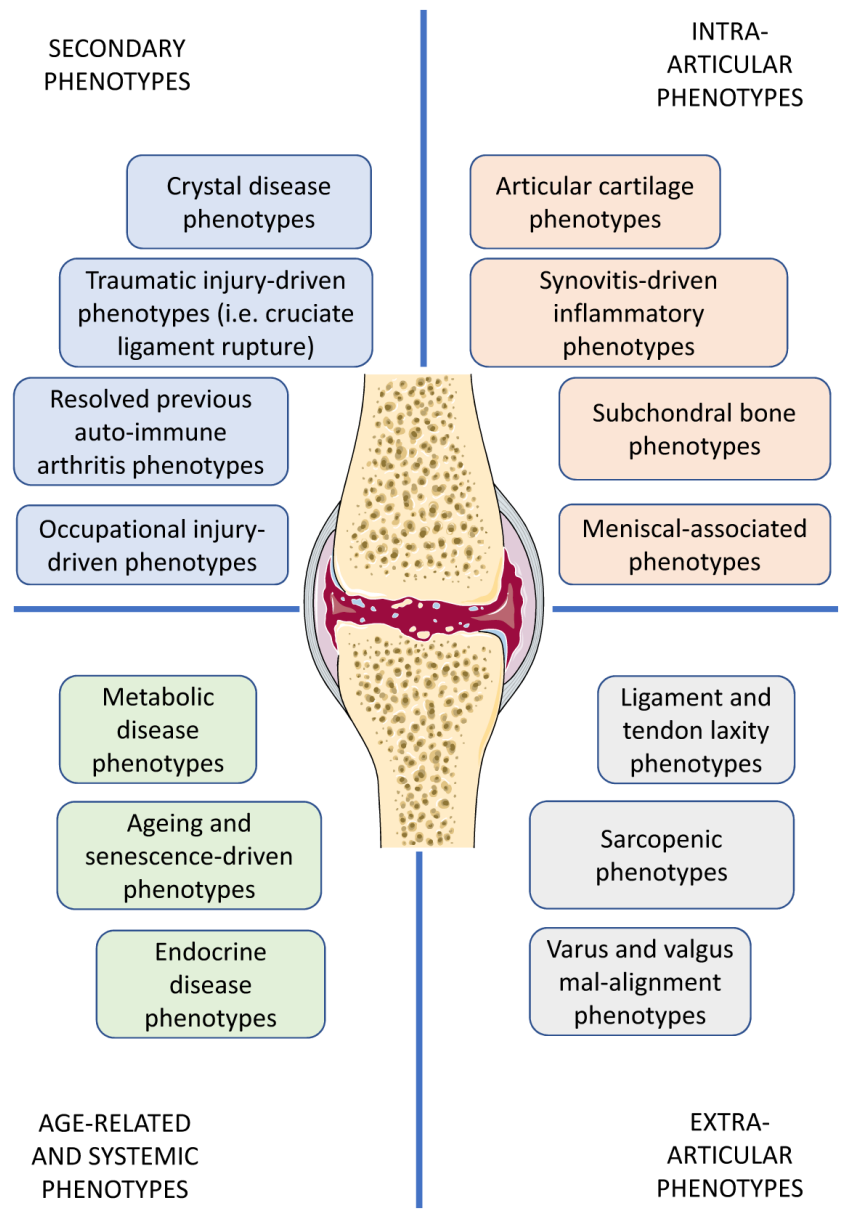

Figure 4. Diverse clinical osteoarthritis phenotypes.

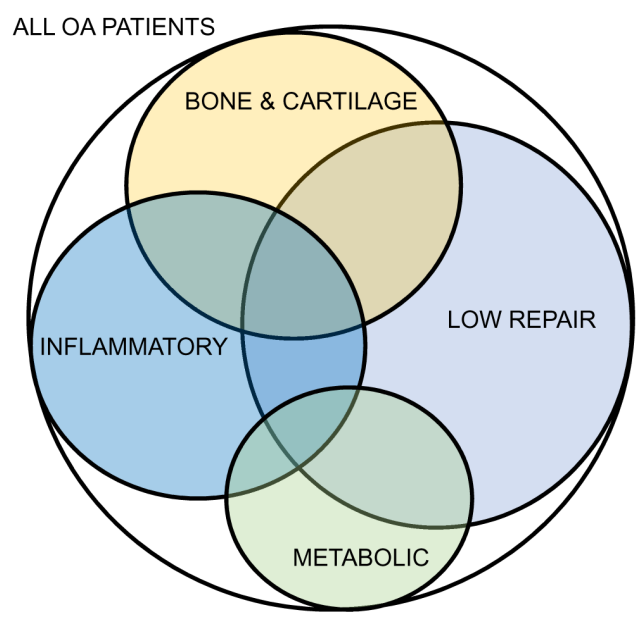

Figure 5. Venn diagram illustrating diverse overlapping molecular endotypes of osteoarthritis. Venn diagram illustrating diverse overlapping molecular endotypes of osteoarthritis (OA). 
The inflammatory phenotype of $\mathrm{OA}$ is the most interesting one from our perspective. The published evidence suggests that synovial inflammation is associated with progressive joint failure, at least in a subgroup of patients, and therefore some OA patients may benefit structurally from an anti-inflammatory intervention ${ }^{46}$. Indeed, the failure to identify and select (molecular) subgroups of OA patients who will benefit most from anti-inflammatory treatments may be the reason why clinical trials targeting inflammation have failed so $\mathrm{far}^{40}$. Synovitis is qualitatively and quantitatively different in OA and RA, but there are significant inflammatory and fibrotic findings observed in the synovium of some OA patients ${ }^{41}$. Synovitis in OA is characterized by macrophage infiltration and activation and is also associated with osteoblast activation and fibrosis ${ }^{47}$. Synovitis in OA also predicts structural progression and varies in parallel with pain. Synovial inflammation is particularly pronounced in a subset of knee OA patients, and those with a prominent inflammatory profile are more likely to respond to NSAIDs ${ }^{48}$. Therefore, pain profiling may also be used to assess patient responses to other drugs such as methotrexate, biologics, steroids, and other emerging anti-inflammatory treatments.

Comparison of RA and OA using microarray profiling of human joint fibroblast-like synoviocytes has revealed important similarities and differences between synovitis in these joint diseases ${ }^{49}$. More detailed examination of fibroblast-like synoviocytes (FLSs) in OA and RA will reveal more about the mechanistic differences between synovitis in these two diseases, but we already know that NF- $\mathrm{KB}$ signaling and tumor necrosis factor $\alpha$ (TNF- $\alpha)$ are also important in synovitis in $\mathrm{OA}^{49}$.

It is important to use standardized techniques and platforms to establish biomarkers of the inflammatory OA phenotype. The laboratory of Virginia Kraus is already making progress in this area by analyzing synovial fluid (SF). A recent study aimed to identify a SF biomarker profile characteristic of individuals with an inflammatory OA phenotype. The authors used a high-sensitivity multiplex immunoassay, Myriad Human InflammationMAP ${ }^{\circledR}$ 1.0, which included 47 different cytokines, chemokines, and growth factors related to inflammation to identify a subset of six SF biomarkers specifically related to synovial inflammation in OA. They also correlated the biomarker profiles to radiographic features and symptom severity. The six OA-related SF biomarkers were specifically found to be linked to indicators of activated macrophages and neutrophils. These results provide the first panel of biomarkers to characterize an inflammatory OA phenotype. This panel of biochemical markers may be measured easily and could serve as the basis for therapeutic targeting of a subset of individuals at high risk for knee OA $\operatorname{progression}^{50}$.
The challenges of studying phenotypes offer the OA research community and pharmaceutical companies involved in developing disease-modifying OA drugs (DMOADs) new and exciting opportunities for innovation. The challenge is to develop sensitive diagnostics that can diagnose the disease in the molecular and pre-radiographic stages and determine which mechanisms are at play. The use of soluble biomarkers will allow more specific targeting of the underlying mechanisms by identifying the key tissues involved (i.e. cartilage, subchondral bone, and synovium). Therefore, panels of biochemical markers will need to be established to define the molecular endotypes of OA. This approach has the capacity to treat and target the disease more effectively. However, finding biomarkers with the sensitivity and specificity to achieve this is a challenging problem in OA biomarker research and currently cannot be done with the currently available biomarkers in our toolbox. A systematic review published by van Spil and colleagues nine years ago concluded that "none of the current biochemical markers are sufficiently discriminating to aid diagnosis and prognosis of OA in individuals or limited numbers of patients or performs so consistently that they could function as an outcome in clinical trials" ${ }^{51}$. The conclusions of this study are still valid today.

\section{Conclusions}

We have learnt a great deal about clinical and molecular endotypes from research into asthma ${ }^{52}$. Now that asthma is known to be a heterogeneous inflammatory disease composed of molecular endotypes, it has been possible to develop targeted therapies as well as biomarkers capable of identifying treatment-responsive patients. We are already using biomarker assays and applications in the research and clinical trial settings to identify clinical and molecular endotypes of severe asthma ${ }^{53}$. The OA research community is several years behind the field of asthma research, but we have the opportunity to identify and apply imaging and biochemical markers to better define the clinical and molecular endotypes of OA. Selecting and targeting of subjects in OA clinical trials will be greatly facilitated by gaining a better understanding of molecular endotypes. This will allow clinical trial designers to recruit subjects who have a high likelihood of responding, and potentially progressing, in a typical clinical trial time period (within 1-2 years in the case of OA) and can aid preclinical decision-making as well as pharmaceutical companies by demonstrating that a drug is successful ${ }^{27}$. However, it is important to note that the subgroups and phenotypes may not segregate clearly and cleanly if we recruit a much older population of OA patients with multiple co-morbidities into clinical trials. It is envisaged that OA patients with a specific molecular endotype present themselves within multiple clinical phenotypic clusters. Some of these phenotypic clusters are likely to overlap, especially in older patients with multiple co-morbidities. 
1. F Hunter DJ, Bierma-Zeinstra S: Osteoarthritis. Lancet. 2019; 393(10182): 1745-59.

PubMed Abstract | Publisher Full Text | F1000 Recommendation

2. F Cross M, Smith E, Hoy D, et al:: The global burden of hip and knee osteoarthritis: estimates from the global burden of disease 2010 study. Ann Rheum Dis. 2014: 73(7): 1323-30.

PubMed Abstract | Publisher Full Text | F1000 Recommendation

3. https://www.who.int/medicines/areas/priority_medicines/Ch6_12Osteo.pdf

4. Lieberthal J, Sambamurthy N, Scanzello CR: Inflammation in joint injury and post-traumatic osteoarthritis. Osteoarthritis Cartilage. 2015; 23(11): 1825-34. PubMed Abstract | Publisher Full Text | Free Full Text

5. Loeser RF, Goldring SR, Scanzello CR, et al:: Osteoarthritis: a disease of the joint as an organ. Arthritis Rheum. 2012; 64(6): 1697-707. PubMed Abstract | Publisher Full Text | Free Full Text

6. Tonge DP, Pearson MJ, Jones SW: The hallmarks of osteoarthritis and the potential to develop personalised disease-modifying pharmacological therapeutics. Osteoarthritis Cartilage. 2014; 22(5): 609-21. PubMed Abstract | Publisher Full Text

7. Cucchiarini M, de Girolamo L, Filardo G, et al.: Basic science of osteoarthritis. J Exp Orthop. 2016; 3(1): 22.

PubMed Abstract | Publisher Full Text | Free Full Text

8. Li G, Yin J, Gao J, et al:: Subchondral bone in osteoarthritis: insight into risk factors and microstructural changes. Arthritis Res Ther. 2013; 15(6): 223 PubMed Abstract | Publisher Full Text | Free Full Text

9. F Hausmann LRM, Youk A, Kwoh CK, et al.: Testing a Positive Psychological Intervention for Osteoarthritis. Pain Med. 2017; 18(10): 1908-20. PubMed Abstract | Publisher Full Text | Free Full Text | F1000 Recommendation

10. Mobasheri A, van Spil WE, Budd E, et al.: Molecular taxonomy of osteoarthritis for patient stratification, disease management and drug development: biochemical markers associated with emerging clinical phenotypes and molecular endotypes. Curr Opin Rheumatol. 2019; 31(1): 80-9. PubMed Abstract | Publisher Full Text

11. Blair JPM, Bager C, Platt A, et al.: Identification of pathological RA endotypes using blood-based biomarkers reflecting tissue metabolism. A retrospective and explorative analysis of two phase III RA studies. PLOS One. 2019; 14(7): e0219980.

PubMed Abstract | Publisher Full Text | Free Full Text

12. F Hinks TSC, Brown T, Lau LCK, et al:: Multidimensional endotyping in patients with severe asthma reveals inflammatory heterogeneity in matrix metalloproteinases and chitinase 3-like protein 1. J Allergy Clin Immunol. 2016; 138(1): 61-75.

PubMed Abstract | Publisher Full Text | Free Full Text | F1000 Recommendation

13. F Svenningsen S, Nair P: Asthma Endotypes and an Overview of Targeted Therapy for Asthma. Front Med (Lausanne). 2017; 4: 158

PubMed Abstract | Publisher Full Text | Free Full Text | F1000 Recommendation

14. Mobasheri A, Bay-Jensen AC, Gualillo O, et al:: Soluble biochemical markers of osteoarthritis: Are we close to using them in clinical practice? Best Pract Res Clin Rheumatol. 2017; 31(5): 705-20. PubMed Abstract | Publisher Full Tex

15. F Bierma-Zeinstra SM, van Middelkoop M: Osteoarthritis: In search of phenotypes. Nat Rev Rheumatol. 2017; 13(12): 705-6. PubMed Abstract | Publisher Full Text | F1000 Recommendation

16. F Anderson GP: Endotyping asthma: new insights into key pathogenic mechanisms in a complex, heterogeneous disease. Lancet. 2008; 372(9643): 1107-19.

PubMed Abstract | Publisher Full Text | F1000 Recommendation

17. Dell'Isola A, Allan R, Smith SL, et al.: Identification of clinical phenotypes in knee osteoarthritis: a systematic review of the literature. BMC Musculoskelet Disord. 2016; 17(1): 425 .

PubMed Abstract | Publisher Full Text | Free Full Text

18. F Fleischmann RM, Bliddal H, Blanco FJ, et al.: A Phase II Trial of Lutikizumab an Anti-Interleukin-1 $\alpha / \beta$ Dual Variable Domain Immunoglobulin, in Knee Osteoarthritis Patients With Synovitis. Arthritis Rheumatol. 2019; 71(7): 1056-69. PubMed Abstract | Publisher Full Text | F1000 Recommendation

19. F Kloppenburg M, Peterfy C, Haugen IK, et al:: Phase Ila, placebo-controlled, randomised study of lutikizumab, an anti-interleukin- $1 \alpha$ and anti-interleukin$1 \beta$ dual variable domain immunoglobulin, in patients with erosive hand osteoarthritis. Ann Rheum Dis. 2019; 78(3): 413-20.

PubMed Abstract | Publisher Full Text | Free Full Text | F1000 Recommendation

20. Goldring SR, Goldring MB: The role of cytokines in cartilage matrix degeneration in osteoarthritis. Clin Orthop Relat Res. 2004; (427 Suppl): S27-S36.

PubMed Abstract | Publisher Full Text
21. F Dell'Isola A, Steultjens M: Classification of patients with knee osteoarthritis in clinical phenotypes: Data from the osteoarthritis initiative. PLoS One. 2018; 13(1): e0191045.

PubMed Abstract | Publisher Full Text | Free Full Text | F1000 Recommendation

22. $\mathrm{F}$ Herrero-Beaumont $\mathrm{G}$, Roman-Blas JA, Bruyère $\mathrm{O}$, et al.: Clinical settings in knee osteoarthritis: Pathophysiology guides treatment. Maturitas. 2017; 96: $54-7$.

PubMed Abstract | Publisher Full Text | F1000 Recommendation

23. Karsdal MA, Christiansen C, Ladel C, et al:: Osteoarthritis--a case for personalized health care? Osteoarthritis Cartilage. 2014: 22(1): 7-16. PubMed Abstract | Publisher Full Text

24. Hunter DJ, Altman RD, Cicuttini F, et al:: OARSI Clinical Trials Recommendations: Knee imaging in clinical trials in osteoarthritis. Osteoarthritis Cartilage. 2015; 23(5): 698-715

PubMed Abstract | Publisher Full Text

25. Okano T, Filippucci E, Di Carlo M, et al.: Ultrasonographic evaluation of joint damage in knee osteoarthritis: feature-specific comparisons with conventional radiography. Rheumatology (Oxford). 2016; 55(11): 2040-9.

PubMed Abstract | Publisher Full Text

26. Mobasheri A, Henrotin Y: Biomarkers of (osteo)arthritis. Biomarkers. 2015; 20(8): 513-8.

PubMed Abstract | Publisher Full Text | Free Full Text

27. Kraus VB, Burnett B, Coindreau J, et al:: Application of biomarkers in the development of drugs intended for the treatment of osteoarthritis. Osteoarthritis Cartilage. 2011; 19(5): 515-42.

PubMed Abstract | Publisher Full Text | Free Full Text

28. Kraus VB, Blanco FJ, Englund M, et al:: Call for standardized definitions of osteoarthritis and risk stratification for clinical trials and clinical use. Osteoarthritis Cartilage. 2015; 23(8): 1233-41.

PubMed Abstract | Publisher Full Text | Free Full Text

29. Orlowsky EW, Kraus VB: The role of innate immunity in osteoarthritis: when our first line of defense goes on the offensive. J Rheumatol. 2015; 42(3): 363-71. PubMed Abstract | Publisher Full Text | Free Full Text

30. F Steinberg J, Ritchie GRS, Roumeliotis TI, et al:: Integrative epigenomics, transcriptomics and proteomics of patient chondrocytes reveal genes and pathways involved in osteoarthritis. Sci Rep. 2017; 7(1): 8935. PubMed Abstract | Publisher Full Text | Free Full Text | F1000 Recommendation

31. Sanchez C, Bay-Jensen AC, Pap T, et al:: Chondrocyte secretome: a source of novel insights and exploratory biomarkers of osteoarthritis. Osteoarthritis Cartilage. 2017; 25(8): 1199-209.

PubMed Abstract | Publisher Full Text

32. Garnero P, Rousseau JC, Delmas PD: Molecular basis and clinical use of biochemical markers of bone, cartilage, and synovium in joint diseases. Arthritis Rheum. 2000; 43(5): 953-68.

PubMed Abstract | Publisher Full Text

33. Mobasheri A: Osteoarthritis year 2012 in review: biomarkers. Osteoarthritis Cartilage. 2012; 20(12): 1451-64

PubMed Abstract | Publisher Full Text

34. Bay-Jensen AC, Reker D, Kjelgaard-Petersen CF, et al.: Osteoarthritis year in review 2015: soluble biomarkers and the BIPED criteria. Osteoarthritis Cartilage. 2016; 24(1): 9-20.

PubMed Abstract | Publisher Full Text

35. Mobasheri A, Matta C, Zákány R, et al:: Chondrosenescence: definition, hallmarks and potential role in the pathogenesis of osteoarthritis. Maturitas. 2015; 80(3): 237-44.

PubMed Abstract | Publisher Full Text

36. van der Kraan P, Matta C, Mobasheri A: Age-Related Alterations in Signaling Pathways in Articular Chondrocytes: Implications for the Pathogenesis and Progression of Osteoarthritis - A Mini-Review. Gerontology. 2017; 63(1): 29-35. PubMed Abstract | Publisher Full Text

37. Ehrlich GE: Osteoarthritis beginning with inflammation. Definitions and correlations. JAMA. 1975; 232(2): 157-9.

PubMed Abstract | Publisher Full Text

38. Ehrlich GE: Osteoarthritis beginning with inflammation. Definitions and correlations. 1975. Bull World Health Organ. 2003; 81(9): 691-3. PubMed Abstract | Free Full Text

39. Rahmati M, Mobasheri A, Mozafari M: Inflammatory mediators in osteoarthritis: A critical review of the state-of-the-art, current prospects, and future challenges. Bone. 2016; 85: 81-90.

PubMed Abstract | Publisher Full Text

40. F Mathiessen A, Conaghan PG: Synovitis in osteoarthritis: current understanding with therapeutic implications. Arthritis Res Ther. 2017; 19(1): 18. PubMed Abstract | Publisher Full Text | Free Full Text | F1000 Recommendation

41. Sellam J, Berenbaum F: The role of synovitis in pathophysiology and clinical 
symptoms of osteoarthritis. Nat Rev Rheumatol. 2010; 6(11): 625-35. PubMed Abstract | Publisher Full Text

42. Sakkas $\mathrm{LI}$, Platsoucas $\mathrm{CD}$ : The role of $\mathrm{T}$ cells in the pathogenesis of osteoarthritis. Arthritis Rheum. 2007; 56(2): 409-24.

PubMed Abstract | Publisher Full Text

43. Kaukinen P, Podlipská J, Guermazi A, et al.: Associations between MRI-defined structural pathology and generalized and localized knee pain - the Oulu Knee Osteoarthritis study. Osteoarthritis Cartilage. 2016; 24(9): 1565-76. PubMed Abstract | Publisher Full Text

44. Koski JM, Saarakkala S, Helle M, et al.: Power Doppler ultrasonography and synovitis: correlating ultrasound imaging with histopathological findings and evaluating the performance of ultrasound equipments. Ann Rheum Dis. 2006; 65(12): 1590-5.

PubMed Abstract | Publisher Full Text | Free Full Text

45. Nevalainen MT, Kauppinen K, Pylväläinen J, et al.: Ultrasonography of the latestage knee osteoarthritis prior to total knee arthroplasty: comparison of the ultrasonographic, radiographic and intra-operative findings. Sci Rep. 2018; 8(1): 17742 .

PubMed Abstract | Publisher Full Text | Free Full Text

46. Siebuhr AS, Bay-Jensen AC, Jordan JM, et al.: Inflammation (or synovitis)-driven osteoarthritis: an opportunity for personalizing prognosis and treatment? Scand J Rheumatol. 2016; 45(2): 87-98.

PubMed Abstract | Publisher Full Text

47. Scanzello CR, Goldring SR: The role of synovitis in osteoarthritis pathogenesis. Bone. 2012; 51(2): 249-57.

PubMed Abstract | Publisher Full Text | Free Full Text
48. $\mathrm{F}$ Petersen $\mathrm{KK}$, Olesen $\mathrm{AE}$, Simonsen $\mathrm{O}$, et al: Mechanistic pain profiling as a tool to predict the efficacy of 3-week nonsteroidal anti-inflammatory drugs plus paracetamol in patients with painful knee osteoarthritis. Pain. 2019; 160(2): 486-92.

PubMed Abstract | Publisher Full Text | F1000 Recommendation

49. F Cai P, Jiang T, Li B, et al:: Comparison of rheumatoid arthritis (RA) and osteoarthritis $(\mathrm{OA})$ based on microarray profiles of human joint fibroblast-like synoviocytes. Cell Biochem Funct. 2019; 37(1): 31-41. PubMed Abstract | Publisher Full Text | F1000 Recommendation

50. F Haraden CA, Huebner JL, Hsueh MF: Synovial fluid biomarkers associated with osteoarthritis severity reflect macrophage and neutrophil related inflammation. Arthritis Res Ther. 2019; 21(1): 146 inflammation. Arthritis Res Ther. 2019; 21(1): 146.
PubMed Abstract | Publisher Full Text | Free Full Text | F1000 Recommendation

51. F van Spil WE, DeGroot J, Lems WF, et al:: Serum and urinary biochemica markers for knee and hip-osteoarthritis: a systematic review applying the consensus BIPED criteria. Osteoarthritis Cartilage. 2010; 18(5): 605-12. PubMed Abstract | Publisher Full Text | F1000 Recommendation

52. Skloot GS: Asthma phenotypes and endotypes: a personalized approach to treatment. Curr Opin Pulm Med. 2016; 22(1): 3-9. PubMed Abstract | Publisher Full Text

53. F Carr TF, Kraft M: Use of biomarkers to identify phenotypes and endotypes of severeasthma. Ann Allergy Asthma Immunol. 2018; 121(4): 414-20.

PubMed Abstract | Publisher Full Text | F1000 Recommendation 


\section{Open Peer Review}

\section{Current Peer Review Status:}

\section{Editorial Note on the Review Process}

Faculty Reviews are review articles written by the prestigious Members of Faculty Opinions. The articles are commissioned and peer reviewed before publication to ensure that the final, published version is comprehensive and accessible. The reviewers who approved the final version are listed with their names and affiliations.

\section{The reviewers who approved this article are:}

\section{Version 1}

\section{Charles J. Malemud}

Department of Medicine, Division of Rheumatic Diseases, Case Western Reserve University School of Medicine, University Hospitals Cleveland Medical Center, Cleveland, OH, 44106, USA

Competing Interests: No competing interests were disclosed.

\section{Rik J U Lories}

Division of Rheumatology, University Hospitals Leuven, KU Leuven, 3000 Leuven, Belgium

Competing Interests: No competing interests were disclosed.

The benefits of publishing with F1000Research:

- Your article is published within days, with no editorial bias

- You can publish traditional articles, null/negative results, case reports, data notes and more

- The peer review process is transparent and collaborative

- Your article is indexed in PubMed after passing peer review

- Dedicated customer support at every stage

For pre-submission enquiries, contact research@f1000.com 